\title{
Noções incontornáveis nas Artes Visuais
}

Unavoidable Notions in Visual Arts

\author{
PRISCILA RAMPIN
}

Universidade de Brasília (UnB) Brasília, Brasil

\section{BEATRIZ RAUSCHER}

Universidade Federal de Uberlândia (UFU) Uberlândia, Brasil

O desafio das pesquisas denominadas estado da arte é mapear a produção científica nas diversas áreas do conhecimento, a fim de discutir os aspectos, as dimensões e os destaques das informações obtidas até o momento do início de novos estudos. Ao usarmos a mesma expressão para denominar o nosso periódico pretendemos resgatar uma modalidade de pesquisa que sistematiza o campo das artes visuais, identifica as investigações realizadas, as tendências temáticas, as abordagens dominantes e as novas, considerando um recorte tanto abrangente, quanto concentrado em nosso contexto geográfico e político.

Ao mesmo tempo, recorremos à aptidão expressiva e ambígua que o termo estado da arte pode ter quando o tomamos metaforicamente. Na expressão, a palavra arte indica um determinado campo, e estado vincula este campo ao modo de ser da arte e às suas circunstâncias.

A proposta temática Noções incontornáveis nas Artes Visuais, do primeiro número da revista Estado da Arte, é amplo para abarcar os inúmeros conceitos que atendam ao interesse e às abordagens dos pesquisadores da arte. 0 tema se confunde com a própria proposta do novo periódico e tem um potencial inesgotável para ser reeditado em outros momentos e em novas chamadas.

Sendo assim, partimos do princípio que os conceitos fundamentais da arte percorrem, de modo incontornável, tanto o trabalho do teórico e historiador, quanto o trabalho do artista, que molda os significados no fazer de sua obra.

Para a primeira chamada convidamos os artistas, os teóricos e os estudiosos da arte para que compartilhassem os caminhos trilhados pelas suas pesquisas e respectivas reflexões sobre os conceitos emergentes da arte e os consagrados, sobre as convergências e divergências entre eles, sobre a atualização e revisão de suas referências. Por fim, que as contribuições resultassem em um repertório renovado de noções que firmam a arte como área do saber.

A produção contemporânea tem explorado a porosidade ou a indeterminação dos limites conceituais e materiais da arte, das categorias e das possíveis definições ontológicas. As abordagens intermidiáticas, as linguagens expandidas e os hibridismos são frequentemente interrogados nas pesquisas artísticas tanto que, nos artigos selecionados para esta edição, verificamos as análises da obra de artistas contemporâneos consagrados como Robert Smithson e Lisa Oppenheim e ainda Bruce Nauman, conduzidas pelas autoras Michal Kirschbaum e Caroline Alciones de Oliveira Leite, respectivamente. 
$\mathrm{Na}$ apresentação de Kirschbaum, a autora questiona a noção de verdade da imagem com base nos trabalhos de Robert Smithson e Lisa Oppenheim. Segundo a autora, esses artistas influenciam a percepção de tempo e de espaço do espectador, lançando mão de estratégias de apropriação e intervenções físicas e culturais. No artigo dedicado à instalação sonora Days, de Bruce Nauman, Leite observa a ideia do espelhamento por meio da repetição de diferentes vozes que se intrometem entre si e o aparato perceptivo do espectador, para projetar-lhe a passagem do tempo investida de expectativas, de alegrias, de frustrações e de finitude. Em ambos os artigos, os espelhos ou a noção de espelhamento como recurso metafórico ou material são recorrentes, e têm o potencial de motivar significações e criar (des)conexões em tópicos sensíveis ao sujeito: a maneira como percebe a continuidade do espaço, a passagem do tempo e a existência humana, sempre permeada por conflitos internos e postos em relação ao mundo exterior.

As proposições de cunho historiográfico, do mesmo modo, debatem as noções fundamentais do campo e, nessa edição, os conteúdos da história da arte buscam novas chaves para a compreensão de obras que apelam às categorias estratificadas do primitivo, do exótico e do marginal.

Emerson Dionísio Gomes de Oliveira apresenta a obra do artista franco-argelino Kader Attia em diálogo com a obra de Pablo Picasso. Seu foco está nas exposições desses artistas que lhe permitem problematizar o conceito de primitivo na arte, assim como as ideias de reparação e apropriação. A análise trazida por Emerson Dionísio indica uma espécie de latência de um porvir dos arquivos e das memórias guardadas nos museus. Sob o escrutínio de renovada leitura do passado, observa o autor, que Attia exacerbou o gesto domesticador, estetizador e apropriador do ocidental para com o continente africano, que pareceram minimizados pela curadoria da exposição Picasso Primitivo, ao deter-se à cronologia histórica da proximidade do artista espanhol com os objetos etnográficos e com a arte primitiva.

Negando-se a discutir a excentricidade da produção de Arthur Bispo do Rosário pelo viés da alienação, Claudia França enfatiza o potencial memorialista de seu trabalho. No artigo são discutidas as operações de listagem e catalogação; as formulações de objeto, coleção, memória e narração no processo de criação de Bispo, marcado pelo uso de matrizes objetuais envolvidas em fios e tecidos coloridos. Para a autora, tal como esses objetos per se, a obra de Bispo é envolvida por uma aura de elementos místicos, lucidez, delírio e loucura, práticas artesanais tradicionais, memórias de viagem, atenção ao cotidiano, presença da palavra escrita, entre outros aspectos. A experiência estética resultante do contato com a obra de Bispo do Rosário, para França, não admite contestar a sua condição de artista.

No sentido de contribuir para a concepção de uma história da arte brasileira global e transnacional, Carlos Henrique Romeu Cabral, procura estabelecer associações entre o campo da geografia da arte e o da história da arte brasileira, num panorama baseado no deslocamento e na circulação de indivíduos e de ideias entre territórios culturalmente distintos. A partir da discussão centro-periferia e através da Geografia da Arte, o artigo de Cabral ressalta a importância e a necessidade de se estudar a produção cultural das periferias artísticas do Brasil, para que o esforço resulte em uma História da Arte brasileira inclusiva, capaz de revisar as narrativas hegemônicas e os processos de exclusão. 
Com olhar voltado ao sistema da arte, a originalidade da pesquisa de Nei Vargas da Rosa está na observação da configuração e do funcionamento de diferentes modelos adotados para dar visibilidade e legitimação a coleções de arte no Brasil. Identificando colecionadoras e colecionadores de arte nas cinco regiões do País, o autor enfatiza as identidades culturais multifacetadas em um país de dimensão continental. Em seu artigo, Vargas pergunta "O que é contemporâneo no colecionismo de arte contemporânea?" para refletir sobre o que pode ser apontado como novo nos processos de institucionalização de coleções privadas de arte contemporânea no Brasil, e quais as contribuições para o desenvolvimento do sistema da arte. Em contraste, o artigo de Luiz Sergio de Oliveira voltase para a insuficiência dos espaços tradicionais e expositivos de uma arte que se fez política e que, colateralmente, coloca em disputa a validade da noção de arte pública como categoria.

Isso porque as noções fundamentais que circunscrevem o campo das Artes Visuais são constantemente reexaminadas. A principal razão é a natureza experimental do fazer artístico, que não hesita em adotar procedimentos e formas de pensar originais, testando a própria definição de obra arte. Assim, os trabalhos efêmeros, os virtuais, os colaborativos ou não, à exemplo da parceria entre o Coletivo Geodésica Cultural e o Projeto Revolução dos Baldinhos da cidade de Florianópolis, ou as ações sensíveis e em escalas ínfimas como as de Mariza Barbosa se mostram, como observa Luiz Sergio de Oliveira, comprometidos com as conexões entre arte, política e as questões sociais na esfera pública.

Na continuidade do primeiro número, lemos sobre trabalhos pouco ou nada preocupados com as premissas institucionais e tradicionais que conferem valor à arte. São artigos que problematizam o reconhecimento de tais práticas e indagam: como atualizar conceitualmente as práticas que expandem a interação e a participação para construir junto? Como a vanguarda de hoje define a experiência vital do trabalho de arte? Suas bases são estéticas ou sociais?

No título do seu artigo, Luiz Sergio de Oliveira situa a vanguarda da contemporaneidade e nos faz (re)avaliar a equivalência da verdade da arte vigente em comparação com a verdade definida, ou perseguida, pelos artistas da primeira metade do século 20, esta última, tributária do encontro radical da subjetividade com o mundo externo e da vontade política de tornar real a utopia de uma sociedade orientada por um único ideal.

Na vertente pública abordada por Oliveira, a arte desafia o princípio de valor histórico e de valor mercadológico que esteve em suas origens. Com base na formulação do autor, constatamos que o Coletivo Geodésica Cultural não está interessado na ocupação do espaço público em substituição ao espaço institucional ou na expansão da quantidade de público, mas numa composição com público que tem a interação e o diálogo como princípio e o enfrentamento das questões sociais e cotidianas como objetivo. 


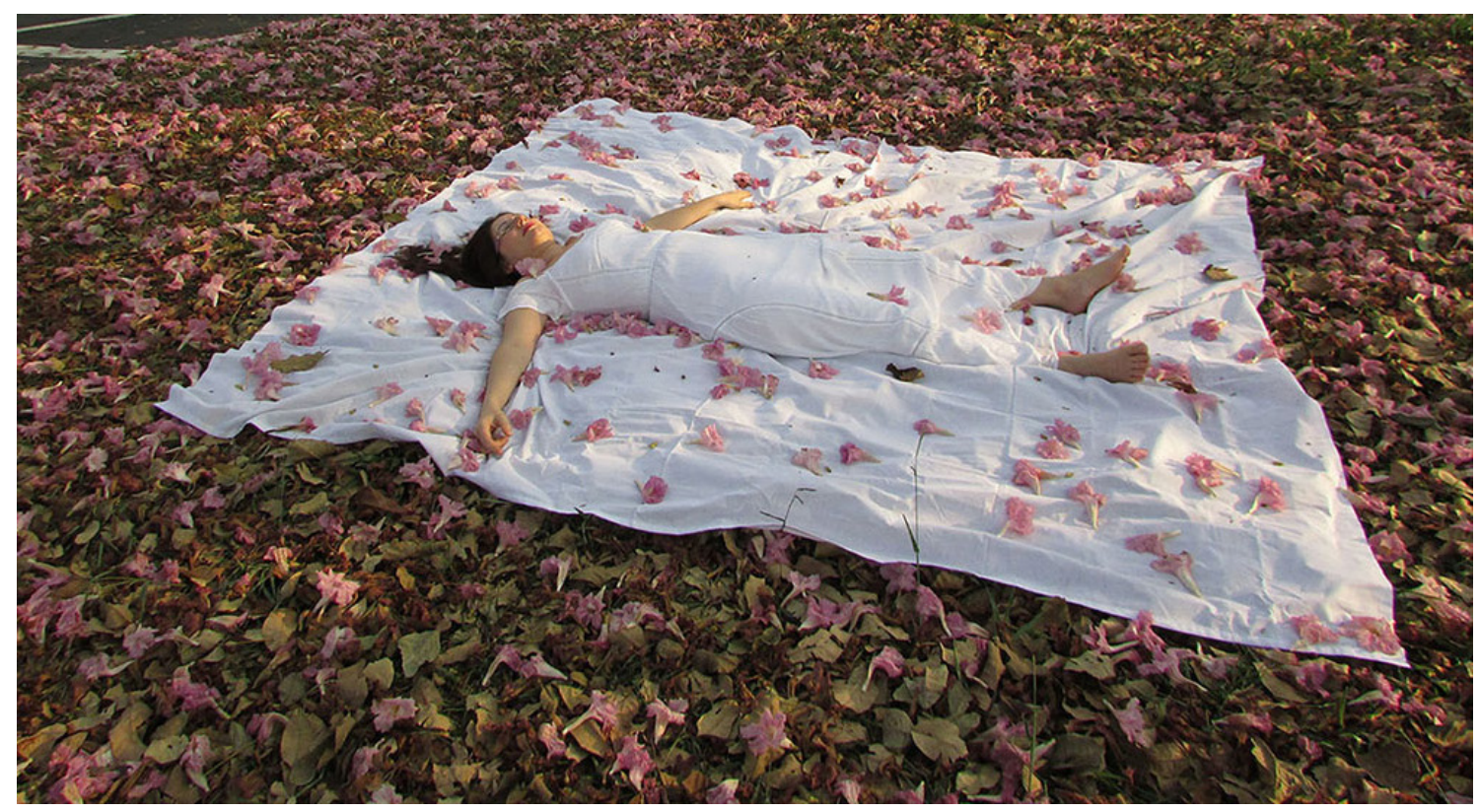

Mariza Barbosa, Está caindo Flor, 2016, performance. Fotografia: Fernando Gomes. Fonte: acervo pessoal da autora.

Outra versão desta modalidade de ação na cidade, é posta à vista com as performances "Está caindo flor" de Mariza Barbosa de Oliveira. A autora/artista nos apresenta a noção de trânsitos poéticos. $O$ espaço público é tomado de modo sensível pela ocupação do corpo em experimentações performáticas, gestos que indicam a necessidade de se discutir tópicos emergentes como o das convenções sociais, nesse caso, a passagem do tempo, a transitoriedade da experiência e a relação com o espectador.

Ainda no contexto do espaço público, Thiago Fernandes busca desenvolver o conceito de mídia tática como ferramenta para ampliação das vozes e anseios de uma cultura. Oferecenos exemplos de manifestações artísticas de baixo orçamento e de elaboração pouco complexa, tipificadas nos moldes do "faça você mesmo" e que circulam constantemente e imediatamente através das mídias de comunicação de massa virtual e/ou efêmera. Lambe-lambes, cartazes, faixas e as ferramentas digitais servem de suporte para mensagens que se infiltram no cotidiano, conturbando a hegemonia dos discursos publicitários e jornalísticos.

Os três artigos mencionados acima, igualmente, marcam atitudes focadas em assuntos mais locais e específicos que afetam o viver em sociedade. Por meio dos seus trabalhos, atestam a insuficiência representativa do sistema político clássico e defendem formas alternativas de micropolíticas.

Completam a presente edição dois artigos e um ensaio curatorial que versam sobre obras de artistas brasileiros associadas às suas respectivas exposições, e às particularidades significantes do local.

O artigo de Pedro Caetano Eboli Nogueira traz um exame dos trabalhos do fotógrafo Vicente de Mello, mostrados no ano de 2018 em duas exposições individuais e simultâneas no Rio 
de Janeiro, uma na Galeria Lurixs e a outra no MAM-RJ; Pedro Paiva e Gabriela Motta discutem a instalação O Ruído do próprio Paiva na I Mostra de Arte [IN]cômodo, realizada na cidade de Pelotas RS em 2016; enquanto Marco Antônio Vieira, apresenta sua curadoria do trabalho de João Angelini no espaço de experimentação artístico-curatorial DeCurators de Brasília DF no verão de 2020.

Nogueira estabelece relações entre o trabalho do artista Vicente de Mello com vertentes da fotografia contemporânea, sublinhando o caráter conceitual e narrativo que permeia a obra de Mello. O autor observa que a poética do artista questiona a relação imagem/referente, além de acionar as noções de memória e coleção na perspectiva do meio fotográfico.

No intuito de compreender o sentido de apropriação de signos da cultura local, Paiva e Motta abordam as características ambientais do trabalho $O$ Ruído em relação ao espaço em que foi instalado. 0 artigo se soma aos trabalhos que discutem a desmaterialização da obra de arte, devido aos recursos materiais que emprega, e, neste caso, a passagem do tempo histórico. Com base na idéia de entropia, que os autores atribuem à matéria escultórica, estabelecem um diálogo entre o espaço institucional e público que abriga a obra e o sal que the dá corpo temporário, aludindo ao período em que o trabalho escravo foi usado como engrenagem de desenvolvimento econômico.

Instauramos, desde já neste primeiro número, uma seção intitulada Curadorias, destinada à difusão de produções curatoriais em artes visuais realizadas pelos autores dos artigos ou propostas originais para publicação no periódico. A seção consiste em apresentar reflexões conceituais de curadores, acompanhadas de um conjunto de imagens ou reproduções visuais das obras dos artistas envolvidos.

Inauguramos a seção com a curadoria de Marco Antônio Vieira, sob o título Cenas de Ódio, Morte e Progresso, elaborada com o políptico instalativo de João Angelini que se desdobra em quatro alegorias. A visão de Vieira, que podemos acompanhar por meio de imagens e textos, aponta para a política genocida de extermínio de populações vulneráveis que marcam a lógica colonialista e tornam a história do Brasil um pesadelo alegórico. Vieira aciona a noção de necropolítica de Achille Mbembe para colocar a ênfase na naturalização discursiva de assassinatos que se legitimam por um conjunto de estratégias intencionais e seletivas de extermínio que a seu ver, se atam ao discurso estético de Angelini.

Por meio de suas experimentações os artistas produzem obras que operam deslocamentos e instauram conceitos inéditos, provocando a necessidade de análises teóricas e de terminologias renovadas. As noções que reconhecemos nesse conjunto de textos: apropriação, intervenção, espelhamento, reparação, temporalidade, entropia, objeto, coleção, memória, cotidiano, trânsitos poéticos e narração determinaram modos de ser da arte, constituindo um vocabulário que não pode ser ignorado.

Outras expressões, que também podem ser observadas nos textos dessa edição, como deslocamento, circulação, legitimação, ocupação, periferias artísticas, visibilidade, identidades culturais, centro-periferia, sistema de arte, arte pública, coleções, mídia tática, micropolítica, necropolítica, indicam meios de apresentação, inserção e recepção nos contextos sociais da arte que valorizam as características geográficas e culturais locais, além de seus produtores. 
Por sua vez, não podemos negligenciar aquilo que não podemos nomear, pois o suporte e o material da arte, segundo nossos autores, operam mudanças, desorganizam as percepções, ampliam os desejos, alteram os modos de pensar a representação, a referencialidade, a identidade, a memória e, de modo mais abrangente, a existência humana. 


\section{Sobre as autoras:}

Priscila Rampin é artista visual e doutoranda em Artes Visuais pela Universidade de Brasília. Mestra pelo Programa de Pós-Graduação em Estudos Contemporâneos das Artes da Universidade Federal Fluminense (2016) e bacharel em Artes Visuais pela Universidade Federal de Uberlândia (2012). Participa do grupo de pesquisa Poéticas da Imagem (UFU/CNPq) e do GEPPA - Grupo de Estudos, Pesquisas e Práticas Artísticas (UNB/CNPq).

Beatriz Rauscher é artista plástica e professora titular da Universidade Federal de Uberlândia. Realizou doutorado em Artes Visuais pela Universidade Federal do Rio Grande do Sul (2005); estágio de doutorado na UFR Cinéma et Audiovisuel de IUniversité Paris III Sorbonne Nouvelle (2003) e pósdoutorado em Arte e Tecnologia da Imagem na Escola de Belas Artes da Universidade Federal de Minas Gerais UFMG (2018). Atualmente é líder do Grupo de Pesquisa Poéticas da Imagem UFU e pesquisadora do Grupo BE-IT: Bureau de Estudos sobre a Imagem e o Tempo da UFMG. 